\title{
Study of Nucleated Red Blood Cell Counts in Asphyxiated Newborns and the Fetal Outcome
}

\author{
Sylvia M Colaco ${ }^{\mathrm{a}, \mathrm{c}}$, Minhajuddin Ahmed $^{\mathrm{a}}$, Vinayak Y Kshirsagar ${ }^{\mathrm{a}}$, Rohit Bajpai ${ }^{\mathrm{b}}$
}

\begin{abstract}
Background: The aim of the study was to find the values of nucleated red blood cells (NRBCs) in normal and asphyxiated babies and their correlation with simple clinical parameter and immediate outcome of such babies.
\end{abstract}

Methods: One hundred forty babies were registered for the study, with 70 as cases and 70 controls. Cord blood was collected and analyzed and the number of NRBCs was determined. It was casecontrol prospective study.

Results: The mean NRBC level in cases and control groups was $17.43 \pm 19.86 / 100$ white blood cells (WBCs) and $2.97 \pm 4.79 / 100$ WBCs respectively $(\mathrm{P}<0.0001)$. The $41.43 \%$ of babies did not develop hypoxic ischemic encephalopathy (HIE). Stage I HIE was seen in $14.28 \%$ of the babies, while stage II and stage III HIE were seen in $31.43 \%$ and $12.86 \%$ babies respectively. The mean NRBCs were 4.48, 11.10, 25.95 and 45.55/100 WBCs in no HIE and stage I, II and III HIE respectively. The NRBC counts are significantly different according to the stages of HIE $(\mathrm{P}<0.0001)$.

Conclusions: NRBCs can be considered as a marker of perinatal asphyxia and significantly correlated with the degree of asphyxia. NRBCs can be used to determine the grade of HIE in asphyxiated neonates.

Keywords: Nucleated red blood cells; Perinatal asphyxia; Neonate

\section{Introduction}

Perinatal asphyxia (derived from the Greek word a-sphyxos,

Manuscript accepted for publication September 15, 2014

${ }^{a}$ Department of Pediatrics, KIMS, Karad, India

${ }^{\mathrm{b}}$ Department of Orthopedics, KIMS, Karad, India

'Corresponding Author: Sylvia M Colaco, "Philrose", Behind Cricket

Ground, Manickpur, Vasai Road (West), Dist-Thane, Pin-401202, India.

Email: silu_dr@yahoo.co.in

doi: http://dx.doi.org/10.14740/ijcp169w meaning born without an evident pulse) is one of the most important causes of fetal distress [1]. Perinatal asphyxia is a serious problem globally, and it is a common cause of neonatal mortality and long-term morbidity. Data from National Neonatal Perinatal Database [2] suggest that perinatal asphyxia contributes to almost $20 \%$ of neonatal deaths in India. Of the 1.2 million neonatal deaths in India every year, 300,000 - 350,000 infants die due to perinatal asphyxia mostly within first 3 days of life [3].

A gold standard definition of birth asphyxia does not exist. It is thus appropriate to use the term perinatal asphyxia as asphyxia may occur in utero, during the process of labor, at birth or in the postnatal period. World Health Organization (WHO) [3] has defined perinatal asphyxia as a "failure to initiate and sustain breathing at birth". National Neonatal Perinatal Database [2] defines moderate asphyxia as slow gasping breathing or an APGAR score of $4-6$ at 1 min of age, and severe asphyxia was defined as no breathing or an APGAR score of $0-3$ at 1 min of age.

Nucleated red blood cells (NRBCs), or erythroblast, are the premature forms of erythrocytes that are commonly found in newborn's blood. Their presence in peripheral blood is associated with the hypoxic nature of fetal growth [4]. Any condition that reduces the quantity of oxygen transported to the tissues can cause an increase in the rate of RBC production. Considering the hematopoietic response to hypoxia in utero the elevated counts of NRBC, it was investigated as a possible marker of asphyxia. Various studies have been conducted to correlate number of NRBCs in cord blood with perinatal asphyxia and have shown a good correlation $[5,6]$. It is a simple test which can be done at rural areas even in primary health centers, which are the backbone of health care in India. So this study aims to find the values of NRBCs in normal and asphyxiated babies and the correlation of number of NRBCs in asphyxiated babies with simple clinical parameter and immediate outcome of such babies.

\section{Materials and Methods}

This study is conducted in the labor room and operation theater of Krishna Hospital and Research Centre, Karad, Ma- 
Table 1. Distribution of Babies According to NRBCs

\begin{tabular}{lllll}
\hline & \multicolumn{2}{c}{ Cases } & \multicolumn{2}{c}{ Control } \\
\cline { 2 - 5 } NRBCs/100 WBCs & Number & Percentage & Number & Percentage \\
\hline $0-10$ & 37 & $52.86 \%$ & 66 & $94.29 \%$ \\
$11-30$ & 20 & $28.58 \%$ & 4 & $5.71 \%$ \\
$31-50$ & 9 & $12.84 \%$ & 0 & $0.00 \%$ \\
$51-70$ & 2 & $2.86 \%$ & 0 & $0.00 \%$ \\
$>71$ & 2 & $2.86 \%$ & 0 & $0.00 \%$ \\
Total & 70 & $100 \%$ & 70 & $100 \%$ \\
\hline
\end{tabular}

harashtra. This study extended from a period of November 2011 to November 2012. It includes 140 babies, and among them 70 were cases which included neonates who had birth asphyxia according to the WHO definition of birth asphyxia. The control babies were selected as the next baby delivered after the birth of an asphyxiated neonate.

Babies satisfying the following criteria according to the definition of birth asphyxia according to WHO, i.e. APGAR score $<7$ at 5 min of life, normal respiration not established at $1 \mathrm{~min}$ after birth and requiring resuscitative measures and heart rate of $<100$ beats/min after 1 min after birth, were included in the study. Babies with severe congenital malformations, chromosomal abnormalities, intrauterine growth retarded babies, babies of diabetic and hypertensive mothers, $\mathrm{Rh}$ incompatibility and babies with history of maternal smoking and chorioamnionitis were excluded from the study.

Babies during the same study period and with an APGAR score $\geq 8$ at $5 \mathrm{~min}$ and meeting the exclusion criteria were included in the control group.

At birth $2 \mathrm{~mL}$ of cord blood was collected in ethylene diamine tetra acetate (EDTA) bulbs in both cases and control groups. The samples were immediately sent to the laboratory for analysis. Other clinical data of the baby and the mother were obtained. Samples were processed and analyzed by the same blinded pathologist. The blood from EDTA bulbs was processed by Lablife 3-part analyzer for obtaining total white blood cells (WBCs), platelet count and hemoglobin. The smears were stained by Leishnman's stain, and manual differential count was done to count percentage of WBCs and NRBCs. The data were analyzed using SSPE and P-value of $<0.05$ was considered statistically significant.

\section{Results}

Out of the 140 babies the male and female distribution was 45 $(64.28 \%)$ and $34(48.58 \%)$ and $25(35.72 \%)$ and $36(51.42 \%)$ in cases and control respectively. There were $17.14 \%$ babies in the cases group whose birth weight was less than 2,000 g and $82.86 \%$ babies with weight more than $2,000 \mathrm{~g}$, whereas

Table 2. Distribution of Cases According to Stages of HIE

\begin{tabular}{lll}
\hline Stage of HIE & Number & Percentage \\
\hline No & 29 & $41.43 \%$ \\
Stage I & 10 & $14.28 \%$ \\
Stage II & 22 & $31.43 \%$ \\
Stage III & 9 & $12.86 \%$ \\
\hline
\end{tabular}


Table 3. Distribution of Babies According to Clinical Characteristics

\begin{tabular}{lllll}
\hline Clinical characteristics & Cases $(\mathbf{n}=\mathbf{7 0})$ & Control $(\mathbf{n}=\mathbf{7 0})$ & $\mathbf{t}$ & $\mathbf{P}$ \\
\hline Number of babies & 70 & 70 & - & - \\
Birth weight $(\mathrm{g})$ & $2,569.11 \pm 511.50$ & $2,751.78 \pm 349.62$ & 2.467 & 0.01 \\
Gestational age (weeks) & $38.21 \pm 2.39$ & $38.93 \pm 1.46$ & 2.12 & 0.03 \\
APGAR at 1 min & $3.86 \pm 0.95$ & $7.5 \pm 0.53$ & 24.95 & $<0.0001$ \\
APGAR at 5 min & $6.31 \pm 0.91$ & $9.51 \pm 0.50$ & 25.75 & $<0.0001$ \\
Maternal age & $24.44 \pm 3.62$ & $24.94 \pm 2.75$ & 0.92 & 0.359 \\
\hline
\end{tabular}

all the babies in the control group had their weight above $2,000 \mathrm{~g}$. The mean birth weight of the babies in the cases group was $2,569.11 \pm 511.50 \mathrm{~g}$ while in control group was $2,751.78 \pm 349.62 \mathrm{~g}$. The most common mode of delivery was normal vaginal route both in control and cases, which was $41(58.57 \%)$ and $44(62.85 \%)$ respectively. This was followed by cesarean section and then instrumental delivery being the least common route. Babies of primiparous mothers were $39(55.73 \%)$ in cases and $40(57.14 \%)$ in control group, and babies of multiparous babies were 31 (44.27\%) and 30 $(42.86 \%)$ respectively in cases group.

Table 1 shows the distribution of babies according to the NRBCs. The number of NRBCs in the control group ranged from 0 to 30 where $94.29 \%$ of the babies had NRBCs between 0 and 10/100 WBCs and only $5.71 \%$ babies had NRBCs $11-30 / 100$ WBCs. In the cases group the NRBCs ranged from 0 to $92 / 100 \mathrm{WBCs}$, whereas $52.86 \%$ had the
NRBCs between 0 and 10/100 WBCs.

The mean NRBC level in cases and control groups was $17.43 \pm 19.86 / 100 \mathrm{WBCs}$ and $2.97 \pm 4.79 / 100 \mathrm{WBCs}$ respectively. This is statistically highly significant $(\mathrm{t}=5.919$ and $\mathrm{P}<0.0001$ ). Table 2 shows the distribution of cases according to the stages of hypoxic ischemic encephalopathy (HIE). Table 3 shows the clinical characteristics of studied population. Mean APGAR scores at $1 \mathrm{~min}$ and $5 \mathrm{~min}$ of age were compared. It was found that the $\mathrm{P}$-value is $<0.0001$, the APGAR scores at $1 \mathrm{~min}$ and $5 \mathrm{~min}$ between the cases group are significantly lower as compared to the control group.

Table 4 shows the laboratory characteristics of studied population. In the present study the mean hemoglobin is $16.38 \pm 1.90 \mathrm{mg} / \mathrm{dL}$ in the cases group and $15.68 \pm 1.45 \mathrm{mg} /$ $\mathrm{dL}$ in the control group. The hemoglobin concentration was significantly higher in the cases group as compared to the babies in the control group $(\mathrm{t}=2.43$ and $\mathrm{P}=0.01)$.

Table 4. Distribution of Babies According to Laboratory Characteristics

\begin{tabular}{lllll}
\hline Laboratory characteristics & Cases $(\mathbf{n}=\mathbf{7 0})$ & Control $(\mathbf{n}=\mathbf{7 0})$ & $\mathbf{t}$ & $\mathbf{P}$ \\
\hline Hemoglobin $(\mathrm{mg} / \mathrm{dL})$ & $16.38 \pm 1.90$ & $15.68 \pm 1.45$ & 2.43 & 0.01 \\
TLC & $21,257.79 \pm$ & $14,343.78 \pm 3,987.3$ & 6.61 & $<0.001$ \\
& $7,788.9$ & & 1.14 & 0.254 \\
Polymorphs & $62.67 \pm 15.19$ & $65.38 \pm 12.77$ & 1.24 & 0.217 \\
Lymphocytes & $35.75 \pm 13.47$ & $32.96 \pm 13.11$ & 1.67 & 0.096 \\
Eosinophils & $0.98 \pm 1.79$ & $1.59 \pm 2.40$ & - & - \\
Monocytes & $0.042 \pm 0.27$ & 0.00 & 1.205 & 0.230 \\
Hemotocrit & $50.46 \pm 6.43$ & $49.34 \pm 4.35$ & 0.023 & 0.984 \\
Platelets & $1.902 \pm 0.64$ & $1.90 \pm 0.79$ & 5.919 & $<0.0001$ \\
NRBCs/100 WBCs & $17.43 \pm 19.86$ & $2.97 \pm 4.79$ & & \\
\hline
\end{tabular}


Table 5. Correlation Coefficient of APGAR at 1 Minute and NRBCs

\begin{tabular}{|c|c|c|c|c|c|c|}
\hline Parameter & Minimum & Maximum & Mean & SD & $\mathbf{r}$ & $\mathbf{P}$ \\
\hline $\begin{array}{l}\text { APGAR at } 1 \\
\text { min }\end{array}$ & 0 & 5 & 3.814 & 1.054 & -0.4396 & 0.0001 \\
\hline NRBCs & 0 & 92 & 17.428 & 19.863 & & \\
\hline
\end{tabular}

The mean total leucocyte count was $21,257.79 \pm 7,788.9 /$ $\mathrm{mm}^{3}$ and $14,343.78 \pm 3,987.3 / \mathrm{mm}^{3}$ in the cases and control group respectively. Thus the mean total leucocyte count was significantly higher in asphyxiated babies as compared to the normal babies $(\mathrm{P}<0.001)$.

Tables 5 and 6 show the coefficient correlation linear regression analysis between the NRBCs of cases group babies with APGAR score at 1 and 5 min respectively. Significant negative correlation was found in cases with APGAR score and NRBCs stating that as APGAR scores decreased the NRBCs increased.

Table 7 shows the characteristics of the NRBC count in cases group according to the stages of HIE. The NRBC counts were compared with the groups of HIE staging using analysis of variants (ANOVA) test. The NRBC counts are significantly different according to the stages of HIE $(\mathrm{F}=$ 21.677 and $\mathrm{P}<0.0001$ ).

By applying Tukey multiple correlation test it was found that the NRBC count has significant difference with the development of HIE in all stages of HIE except between in stages of no HIE versus stage I HIE which can be seen in Table 8 .

\section{Discussion}

Asphyxia remains one of the main causes of later disability in term infants. Despite many studies identifying possible predictors of outcome in this population of interest, little is known about the long-term neurodevelopmental outcome of asphyxiated term neonates. It is now being suggested that birth asphyxia should only be diagnosed when the baby goes on to develop HIE which has shown to be a much more reliable indicator of long-term handicap than any other perinatal markers. The hematopoietic response to hypoxia in utero, the elevated NRBCs/100 WBC count is being hailed as the marker for not only perinatal asphyxia but also the chances of the neonate to go on to develop neurological sequelae.

In the present study the most common mode of delivery in the cases group was vaginal delivery. This is contradictory to all other studies where the most common mode of delivery in asphyxiated neonates is caesarean section. Our results only correlate with the results of Boskabadi et al [7] who carried out a study on 48 perinatally asphyxiated neonates and the most common mode of delivery was normal vaginal route in 34 of these babies. In a study by McCarthy et al [8] concluded that stress of uncomplicated labor does not change NRBC levels. Thus the variation in different studies regarding the mode of delivery may be explained by the fact that neonatal encephalopathy may originate early in neonatal period in some cases of HIE.

In our study normal vaginal delivery being the commonest mode of delivery could also be attributed to the fact that we are a tertiary care center in rural areas, the patients come from far-off rural villages and the time taken for reaching the hospital is longer due to unavailability of transport. By the time the women reach the hospital the labor has progressed and has completed second stage of labor. So they deliver

Table 6. Correlation Coefficient of APGAR at 5 Minutes and NRBCs

\begin{tabular}{|c|c|c|c|c|c|c|}
\hline Parameter & Minimum & Maximum & Mean & SD & $\mathbf{r}$ & $\mathbf{P}$ \\
\hline $\begin{array}{l}\text { APGAR at } 5 \\
\min \end{array}$ & 4 & 7 & 6.314 & 0.909 & -0.4544 & $<0.0001$ \\
\hline NRBCs & 0 & 92 & 17.428 & 19.863 & & \\
\hline
\end{tabular}


Table 7. NRBC Count According to the Stage of HIE

\begin{tabular}{|c|c|c|c|c|}
\hline NRBCs/100 WBCs & No HIE & Stage I & Stage II & Stage III \\
\hline Minimum & 0.00 & 0.00 & 5.00 & 14.00 \\
\hline Maximum & 25.00 & 28.00 & 63.00 & 92.00 \\
\hline Mean & 4.48 & 11.10 & 25.95 & 45.55 \\
\hline SD & 6.180 & 9.036 & 17.622 & 25.880 \\
\hline
\end{tabular}

quickly once they reach the hospital.

NRBCs are present in the placental vessels through the first half of pregnancy, but are uncommon later in pregnancy and are usually absent or present only in small numbers at term. Many conditions can be associated with an increase of NRBCs in neonates, but Fox [9] found that acute asphyxia was the most common of these causes. In the present study there is a high significant statistical correlation in the two groups. Statistical correlation is found in all other studies conducted on similar basis [7, 10-15].

The normal values of NRBCs/100 WBCs have been given by different authors by various studies conducted over the years. Shivhare et al [16], Sinha et al [17], Phelan et al [18] and Hanlon-Lundberg et al [19] have conducted studies in term babies with NRBCs/100 WBCs values checked on cord blood samples and have found values like 4.1, 2.3, 3.4 and 8.5 respectively. The values of $0-10 \mathrm{NRBCs} / 100$ WBCs are typical, and values above $10-20 \mathrm{NRBCs} / \mathrm{WBC}$ are elevated, although these values are highly dependent on the total leucocyte count.

In the present study the NRBCs value in the cord blood sample of asphyxiated neonates ranged from 0 to $92 \mathrm{NRBCs} /$ WBC. The $52.86 \%$ of neonates had a value ranging from 0 to
$10 \mathrm{NRBCs} / \mathrm{WBC}$ which means they were within the normal range of NRBCs in cord blood of neonates. All of these babies developed either no features of HIE or features of stage I HIE and were all discharged in good health. Babies with higher NRBCs/WBC count at birth developed higher stages of HIE.

Out of the 70 asphyxiated neonates studied, $41.43 \%$ babies showed no signs of HIE according to Sarnat and Sarnat's staging for HIE development. Ten neonates (14.28\%) developed features suggestive of stage I HIE, $31.43 \%$ of neonates developed stage II HIE and $12.86 \%$ neonates developed stage III HIE respectively. We had maximum number of neonates who did not develop HIE as compared to a study by Shivaprakash et al (2013) [15] where only $8 \%$ babies and Boskabadi et al (2010) [7] where only $14.28 \%$ of babies did not develop HIE. Similarly $12.86 \%$ of our babies developed stage III HIE which is comparable to a study by Shivaprakash et al (2013) [15] where $12 \%$ babies developed stage III HIE. Table 9 shows the comparison of NRBC with stages of HIE in various studies. The mean NRBC values in different stages of HIE were compared; the data were statistically highly significant $(\mathrm{P}<0.0001)$.

Multiple comparisons between the mean NRBC value of

Table 8. Multiple Comparison Between HIE Stages and NRBCs

\begin{tabular}{llll}
\hline Groups & Mean deviation & $\mathbf{q}$ & $\mathbf{P}$ \\
\hline No HIE vs. stage I & -6.617 & 1.772 & $>0.05$ \\
No HIE vs. stage II & -21.472 & 7.459 & $<0.001$ \\
No HIE vs. stage III & -40.073 & 10.315 & $<0.001$ \\
Stage I vs. stage II & -14.855 & 3.825 & $<0.05$ \\
Stage I vs. stage III & -33.456 & 7.152 & $<0.001$ \\
Stage II vs. stage III & -18.601 & 4.617 & $<0.01$ \\
\hline
\end{tabular}


Table 9. Comparison of NRBCs With Stages of HIE in Various Studies

\begin{tabular}{|c|c|c|c|c|}
\hline \multirow{3}{*}{ HIE Stage } & \multicolumn{3}{|c|}{ NRBCs } & \multirow[b]{3}{*}{ Present study } \\
\hline & & & & \\
\hline & $\begin{array}{l}\text { Shivaprakash et al } \\
\text { (2013) [15] }\end{array}$ & $\begin{array}{l}\text { SJ Fern et al } \\
(2004)[20]\end{array}$ & $\begin{array}{l}\text { Boskabadi et al } \\
\text { (2010) [7] }\end{array}$ & \\
\hline No HIE & $7.25 \pm 5.32$ & 0 & 9.75 & $4.48 \pm 6.18$ \\
\hline HIE I & $10.43 \pm 3.68$ & 5.61 & 11.94 & $11.10 \pm 9.03$ \\
\hline HIE II & $18.63 \pm 3.22$ & 8.25 & 21.08 & $25.95 \pm 17.62$ \\
\hline HIE III & $30.83 \pm 4.49$ & 12.42 & 29.18 & $45.55 \pm 25.88$ \\
\hline $\mathrm{P}$ & 0.001 & $<0.000$ & $<0.001$ & $<0.0001$ \\
\hline
\end{tabular}

various stages of HIE showed statistical correlation between all stages of HIE except stage I and neonates with no features of HIE. Similar correlations between the control and the various cases groups were also reported by Shivaprakash et al [15] and Ferns et al [20]. Phelan et al [18] showed that all neonates with neurological impairment secondary to perinatal asphyxia had a significantly higher number of NRBCs $/ 100$ WBCs than control group $(\mathrm{P}<0.00001)$. Mohammed et al [13] reported that increase in number of NRBCs is an early marker to detect asphyxia and subsequent neurological impairment and stages of HIE.

In the present study we found a significant statistical correlation between NRBCs/100 WBC counts at both $1 \mathrm{~min}$ and 5 min $(\mathrm{P}<0.0001)$. Multiple comparison between HIE staging and APGAR scores at 1 and 5 min showed a significant correlation between neonates who showed no signs of HIE with babies with stage III HIE. The limitations in our study were: as the sample size was small we could not predict which of the inclusion criteria is a better predictor of perinatal asphyxia, and we did not study the $\mathrm{pH}$ of the cord blood, thereby the relationship between acidosis and NRBC counts could not be established. Study did not consider the time taken for the NRBCs to clear out from the neonatal venous blood, thus it could not study the parameters regarding the clearance of NRBCs for neonatal blood and its importance.

Hence from our study we conclude that umbilical cord NRBCs/100 WBC counts can be used as a marker for perinatal asphyxia.

\section{Conclusion}

NRBCs can be considered as a marker of perinatal asphyxia and their levels can be significantly correlated with the degree of asphyxia. They can be used to determine the grade of HIE in asphyxiated neonates. A simple, cheap, rapid and non-invasive test of NRBC count, obtained from otherwise discarded sample of cord blood provided valuable information about the well being of the newborn and correlates well with APGAR score. Babies delivered in primary health care centers can be referred for further care to neonatal intensive care centers. And by applying new approaches in treatment like the neuroprotective techniques such as hypothermia, anti-oxidant therapy and other modalities of treatment, the CNS morbidity levels can be reduced.

\section{Grant Support}

None.

\section{Conflict of Interest}

None.

\section{References}

1. Steer PJ, Danielian P. Fetal distress in labour. In: James, Steer, Weiner, Gonik. High risk pregnancy. 3rd edition. WB Saunders. 2005;1450-1471.

2. National Neonatal and Perinatal Database Report. 20022003.1-58.

3. World Health Organization.Neonnatal and Perinatal Mortality; Country, Regional and Global estimates, 
2004; WHO,Geneva. 2006; 1-25.

4. Lippman HS. Morphologic and quantitative study of blood corpuscles in the newborn period. America Journal of Diseases in Children.1924;27:473-515.

5. Green DW, Mimouni F. Nucleated erythrocytes in healthy infants and in infants of diabetic mothers. J Pediatr. 1990;116(1):129-131.

6. Ghosh B, Mittal S, Kumar S, Dadhwal V. Prediction of perinatal asphyxia with nucleated red blood cells in cord blood of newborns. Int J Gynaecol Obstet. 2003;81(3):267-271.

7. Boskabadi H, Maamouri G, Sadeghian MH, GhayourMobarhan M, Heidarzade M, Shakeri MT, Ferns G. Early diagnosis of perinatal asphyxia by nucleated red blood cell count: a case-control study. Arch Iran Med. 2010;13(4):275-281.

8. McCarthy JM, Capullari T, Thompson Z, Zhu Y, Spellacy WN. Umbilical cord nucleated red blood cell counts: normal values and the effect of labor. J Perinatol. 2006;26(2):89-92.

9. Fox H. The incidence and significance of nucleated erythrocytes in the foetal vessels of the mature human placenta. J Obstet Gynaecol Br Commonw. 1967;74(1):40-43.

10. Papa D, Jyotsna P, Ashok BB. Cord blood nucleated red blood cell count-a marker of fetal asphyxia. J Obstet Gynecol India. 2008;58:45-48.

11. Sikarwar GS, Gupta S. The Correlation Of Clinical Perinatal Asphyxia With Counts Of Nrbc/100 Wbc In Cord Blood. Webmed Central Obstetrics And Gynaecology. 2011;2(1):WMC001511.

12. Kovalak EE, Dede FS, Gelisen O, Dede H, Haberal A. Nonreassuring fetal heart rate patterns and nucleated red blood cells in term neonates. Arch Gynecol Obstet.
2011;283(5):1005-1009.

13. Mohammed LH, Mohammed NR, AL-Hussieny NA, Rezq SH. Early Predictions of Hypoxic-Ischemic Encephalopathy by Umbilical Cord Nucleated Red Blood Cells and Lactate Med. J Cairo Univ. 2011:79(1):625631.

14. Alam F, Aziz M, Ali SM, Hakim S, Afroz N. Evaluation of hematological profile of cord blood and placental histopathology in neonates with perinatal asphyxia. Curr Pediatr Res. 2012;16(2):105-110.

15. Shivaprakash NC, Nigam G. Prediction of HIE by nucleated RBC's in cord blood, serum creatine kinase and assessment of outcome by follow up up to 6 months. Journal of Evolution of Medical and Dental Sciences. 2013:2(19):3340-3348.

16. Shivhare K, Chawla K, Khan MA, Mathur PS. Effect of maternal toxaemia on total haemoglobin, foetal haemoglobin and nucleated red blood cells in cord blood. Indian J Pediatr. 1976;43(346):349-356.

17. Sinha HB, Mukherjee AK, Bala D. Cord blood haemoglobin (including foetal haemoglobin), and nucleated red cells in normal and toxaemic pregnancies. Indian Pediatr. 1972;9(9):540-543.

18. Phelan JP, Ahn MO, Korst LM, Martin GI. Nucleated red blood cells: a marker for fetal asphyxia? Am J Obstet Gynecol. 1995;173(5):1380-1384.

19. Hanion-Lundberg KM, Kirby RS, Gandhi S, Broekhuizen FF. Nucleated red blood cells in cord blood of singleton term neonates. Am J Obstet Gynecol. 1997;176(6):1149-1154; discussion 1154-1146.

20. Ferns SJ, Bhat BV, Basu D. Value of nucleated red blood cells in predicting severity and outcome of perinatal asphyxia. Indian J Pathol Microbiol. 2004;47(4):503-505. 